\title{
Optimism and the Boundaryless Career: The Role of Developmental Relationships
}

\section{Citation}

Higgins, Monica C., Shasa Dobrow, and Kate Roloff. 2010. Optimism and the boundaryless career: The role of developmental relationships. New Directions for Boundaryless Careers. Special Issue. Journal of Organizational Behavior 31(5): 749-769.

\section{Published Version}

doi:10.1002/job.693

\section{Permanent link}

http://nrs.harvard.edu/urn-3:HUL.InstRepos:5372958

\section{Terms of Use}

This article was downloaded from Harvard University's DASH repository, and is made available under the terms and conditions applicable to Open Access Policy Articles, as set forth at http:// nrs.harvard.edu/urn-3:HUL.InstRepos:dash.current.terms-of-use\#OAP

\section{Share Your Story}

The Harvard community has made this article openly available.

Please share how this access benefits you. Submit a story.

\section{Accessibility}




\section{A DIGITAL ACCESS TO SCHOLARSHIP AT HARVARD}

\section{Optimism and the Boundaryless Career: The Role of Developmental Relationships}




\title{
OPTIMISM AND THE BOUNDARYLESS CAREER:
}

\section{THE ROLE OF DEVELOPMENTAL RELATIONSHIPS}

\author{
Monica Higgins \\ Shasa Dobrow \\ Kate Roloff
}

Keywords: boundaryless careers, optimism, psychological capital, developmental relationships 
Optimism and the Boundaryless Career 2

\begin{abstract}
This research explores an important psychological capacity in the current boundaryless career environment - optimism. Optimism has been associated with flexibility and adaptability amidst stressful situations (Shifren \& Hooker, 1995), which, we argue here may be particularly useful in the current unpredictable career environment. We explore the relationship between optimism and the structure and quality of individuals' developmental networks in a sample of young adults. Analyses are based upon a 10-year longitudinal study (1996-2006) of a cohort of 136 individuals who graduated from business school in 1996. Cross-sectional analyses show that the amount of psychosocial support received by individuals, but not career support, is positively associated with optimism. Then, considering the longer-term nature of help-giving, longitudinal relational data suggest that the greater one's early-career psychosocial and career support, the greater one's optimism many years hence. In addition, we examined how the rate of change in developmental network support over time is associated with optimism. Findings show that increasing amounts of career and psychosocial support over time were associated with greater optimism later in career. Implications for future research on the boundaryless career, optimism, and developmental relationships are discussed.
\end{abstract}


In the fifteen years since the concept of the "boundaryless career" was first introduced in the Journal of Organizational Behavior (Arthur, 1994) and then developed in the book The Boundaryless Career (Arthur \& Rousseau, 1996), the nature of the career environment has changed substantially. Then, career scholars were writing about the shift from the traditional “organization man" view of employment (Whyte, 1956) to a model in which individuals would become more self-directed and "protean" (Hall, 1976; Hall \& Mirvis, 1995) as they navigated their careers. In essence, the responsibility for career management had transitioned from the employer to the employee. Today, although the theme of change in individuals' careers persists, the drivers of career change have evolved quite a bit, given new challenges facing employees and employers. Since the mid-1990s, we have witnessed an increasing number of external shocks to the labor markets that have reduced the amount of stability felt by individuals. Not only has the nature of employment arrangements become less predictable, but the environmental context in which organizations themselves must operate has become less stable. In order to navigate the present-day career environment, we propose that there is an increasing need for individuals to build psychological capacities such as efficacy, hope, resilience, and optimism (Luthans, Avolio, Avey, \& Norman, 2007).

Consider, for example, external shocks over the past decade in both the United States and more broadly such as the emergence of an entirely new way of doing business due to the internet; employment disruptions associated with the dot-com boom and bust; instability in the political and economic environment following the tragedies of September 11, 2001 (9/11); and natural disasters across the globe, including the Southeast Asian Tsunami and Hurricane Katrina that have threatened even basic opportunities for work and well-being. Consider as well the present-day worldwide economic and financial crisis that has threatened individuals' security 
regarding employment and employability and altered opportunities for the kinds of flexibility and "protean careers" (Hall \& Mirvis, 1995) that were hallmarks of the original boundaryless career research. Today, organizational and career scholars have become increasingly concerned with finding ways to help individuals persevere amidst such factors that are seemingly unpredictable and uncontrollable (e.g., Spreitzer, Sutcliffe, Dutton, Sonenshein, \& Grant, 2005). These environmental changes have motivated researchers to consider important yet often-ignored aspects of work life such as hope, optimism, and resilience (Seligman, 2002). As Luthans and colleagues (2007) conclude, “employees who are more hopeful, optimistic, efficacious, and resilient may be more likely to 'weather the storm' of the type of dynamic, global environmental contexts confronting most organizations today than their counterparts with lower psychological capital” (p. 568).

In this study, we focus on one particular aspect of this new notion of psychological capital — optimism — as it relates to the support individuals receive from developmental relationships in their careers. Recent research shows that optimism is positively associated with important career outcomes such as job satisfaction, work happiness, organizational commitment, and performance (Kluemper, Little, \& DeGroot, 2009; Youssef \& Luthans, 2007). Further, research shows that optimists are less likely to dwell on negative or stressful situations, less likely to give up amidst stress, and are more likely to maintain a positive outlook and to develop plans of action to deal with stressful situations (e.g., Peterson \& Seligman, 1984; Shifren \& Hooker, 1995; Strack, Carver, \& Blaney, 1987). We propose that these are exactly the kinds of capacities needed in the present-day career environment. Thus, we focus specifically on the concept of optimism in the present research. 
Our study of optimism and its relationship to developmental networks contributes to boundaryless career research in several respects: First, we build upon the idea that social capital is important in a boundaryless career environment (Raider \& Burt, 1996) and that developmental relationships in particular are critical to consider (Higgins \& Thomas, 1996). These ideas were offered in the original boundaryless careers volume (Arthur \& Rousseau, 1996) and are well aligned with Hall's (1996) "relational approach to careers." Here, we extend this prior work by empirically examining the role that the timing, amount, and kind of support provided by an individual's developmental network can play in an individual's career. Further, with this study's focus on optimism, we address recent calls for greater attention to subjective as well as objective career outcomes (Hall \& Chandler, 2005). And, by connecting boundaryless career research with the emerging field of positive psychology, we offer a new lens for career research —one that considers psychological capital as well as social capital in the present-day environment. To address our core research question-regarding the association between optimism and individuals' developmental networks — we draw upon data from a ten-year study (1996-2006) of a cohort of 136 individuals who graduated from business school in 1996.

\section{Theoretical Background}

\section{Optimism as a Developable Capacity}

Concurrent with the introduction of the "boundaryless career" in the scholarly realm, practitioners began to investigate the notion of a "career-resilient workforce" (Waterman, Waterman \& Collard, 1994). This work focused on the role of the organization in helping individuals become more self-reliant in their careers. In particular, it paid attention to the ways in which organizations could help employees "benchmark" and "update their skills," "prepare for the future," and engage in "self assessment" to become more "competitive." The focus of this 
work was on the role or even "obligation" of the employer to help individuals explore new opportunities or become more protean in their careers (Mirvis \& Hall, 1994).

Then, in the early 2000s, the employment context shifted amidst tragedies such as $9 / 11$, and scholars became drawn toward research with a focus on "what is good about life" and developed the sense that these constructs were as important to study as "what is bad" (see Peterson, 2006, p. 4). This view stood in contrast to prior work in psychology, which, since World War II, had focused on individuals' pathologies (Seligman, 2002). In organizational theory, a new field — positive organizational scholarship (POS) — emerged. It focuses on "the study of especially positive outcomes, processes, and attributes of organizations and their members," including the factors, such as relationships, that enable such positive outcomes (Cameron, Dutton, \& Quinn, 2003, p. 4).

More recently, organizational scholars in the related field of Positive Organizational Behavior (POB) have engaged in research at the micro and meso-levels of analyses and have examined how different kinds of psychological resources or "psychological capital" such as hope, optimism, efficacy, and resilience are important capacities for work and life (Luthans et al., 2007; Spreitzer et al., 2005). As Youssef and Luthans (2007) demonstrated in a study of positive organizational behavior in the workplace, dimensions of psychological capital, such as optimism, are positively associated with important career outcomes such as work satisfaction and performance. Further, as they propose, individual capacities, such as optimism, may be considered "states" and so, fall in the middle of a continuum anchored by trait-like characteristics, which are stable individual difference factors (e.g., personality) and momentary positive states that are changeable (e.g., mood) (Luthans, 2002; Luthans \& Youssef, 2007; Luthans et al., 2007; Youssef \& Luthans, 2007). As states, capacities such as optimism are now 
viewed as being open to change or developable (Avolio \& Luthans, 2006) and hence, are potential levers for change in the workplace (Kluemper et. al., 2009; Peterson, 2000).

Research in other areas of psychology, such as care-giving, have similarly suggested that considering optimism as a state may be especially useful when studying individuals' responses to stressful contexts because it provides insight into how individuals are able to put their negative feelings aside and focus on ways to deal with difficult problems (Shifren \& Hooker, 1995). As a working definition of optimism, Shifren and Hooker (1995) suggest that optimism is "the current expectancy that positive outcomes will occur in the future" (p. 61). Similarly, Youssef and Luthans (2007) recently argued for a focus on state forms of optimism in organizational research. Drawing from Seligman (1998), they defined optimism as an "attributional style that explains positive events in terms of personal, permanent, and pervasive causes and negative events in terms of external, temporary, and situation-specific ones" (Youssef \& Luthans, 2007, p. 778). Theoretical and empirical research shows that optimism may be considered state-like (e.g., Schneider, 2001; Seligman, 1998; Shifren \& Hooker, 1995), can be measured reliably (e.g., Kluemper et. al., 2009), and can have a positive impact on performance at work (e.g., Youssef \& Luthans, 2007). In addition, recent research now suggests that relative to trait optimism, state optimism is a better predictor of certain career-related outcomes such as job satisfaction and affective commitment (Kluemper et. al., 2009).

Several aspects of these recent conceptualizations of optimism are consistent with boundaryless career research. First, the view of optimism as a developable or state-like capacity is consonant with the central role that personal learning has always played in boundaryless career research (e.g., Kram \& Hall, 1989, 1995; Weick, 1996). Second, and in line with the emphasis on relationships that has been central to boundaryless career research (e.g., Higgins \& Thomas, 
1996), recent research on positive psychological resources has emphasized the role that positive relationships can play in developing these capacities (Spreitzer et al., 2005). Positive connections can be a source of protection as well as a resource that can promote positive kinds of behaviors and attitudes at work (Cameron et al., 2003; Dutton \& Heaphy, 2003; Spreitzer et al., 2005). Thus, optimism, like other kinds of psychological capacities (e.g., thriving at work), may be positively associated with supportive relationships in one's career.

\section{Developmental Relationships and Optimism}

In the present context, one can then reasonably ask, what kinds of relationships are likely to matter with respect to optimism? Is it sufficient to have growth-enhancing positive relationships or are there particular kinds of help that are especially important when it comes to cultivating optimism? To address these questions, we turn to the mentoring literature, which has studied capacity-enhancing relationships for decades (Kram, 1985; Livingston, 2003).

The mentoring literature has traditionally viewed a "mentor" as a senior individual within one's own employing organization who provides both career support, a type of support characterized by sponsorship, exposure, and protection, and psychosocial support, a type of support characterized by friendship and caring beyond work (Kram, 1985). Mentoring has long been recognized as critical to the development of young adults (Livingston, 2003). In the career field, mentoring has been associated with positive outcomes such as promotion and career advancement (Whitely, Dougherty \& Dreher, 1991; Zey, 1984). Over the years, distinctions have emerged between different kinds of developers - for example, between true "mentors" who provide high amounts of both career and psychosocial support, "sponsors" who primarily provide career support (Thomas \& Kram, 1988), "friends" who primarily provide psychosocial 
support, and "allies" who provide low amounts of both psychosocial and career support (Cummings \& Higgins, 2005; Higgins, 2007).

Building on this notion that different people may provide different kinds and amounts of support, scholars have re-conceptualized mentoring by employing a "developmental network" perspective (Higgins \& Kram, 2001). A developmental network is the "set of people a protégé names as taking an active interest in and action to advance the protégé's career by providing developmental assistance" (Higgins \& Kram, 2001: 268). When adopting a developmental network perspective to the study of mentoring at work, researchers consider the full and potentially interconnected set of individuals both inside and outside one's place of work who provide psychosocial and career support to an individual at any one point in time (Higgins \& Kram, 2001).

Developmental networks are subsets of an individual's entire network or social capital; they are generally small in size - about five people — which is similar to other content-specific networks (Podolny \& Baron, 1997). These relationships may span organizational boundaries and so, may be with friends, family, community members, and/or colleagues (Higgins \& Thomas, 1996). Studies of developmental networks have examined how the extra-organizational nature of such ties impact protégé outcomes such as organizational commitment, work satisfaction, clarity of professional identity, and career advancement (Dobrow \& Higgins, 2005; Higgins, 2001; Higgins \& Thomas, 2001). Here, we extend prior boundaryless career research on developmental relationships (e.g., Higgins \& Thomas, 1996) by investigating how the timing, amount, and kind of support provided by individuals' developmental networks are associated with optimism in the careers of young adults.

\section{Hypotheses}




\section{A Snapshot in Time: Developmental Support and Optimism}

We examine the relationship between developmental support and optimism in three different ways. We note that our goal throughout is not to make definitive claims regarding causality, but rather to use ten years of relational information to gain deeper insight into potential linkages between optimism and developmental support. With that in mind, first, we examine how the type and amount of support are associated with optimism at a particular point in time. This cross-sectional perspective does not establish causality; indeed, one could argue that having a favorable outlook yields greater help-seeking and hence, more in-depth relationships. However, it is also likely that having positive supportive relationships yields positive expectations about the future, consistent with optimism. In particular, the greater the psychosocial support from one's developmental network, the more emotionally supported one should feel, enhancing one's self-confidence (Kram, 1985) and positive expectations about the future. Further, the greater the career support from one's network of developmental relationships, the greater one's exposure, visibility, and sponsorship (Kram, 1985), all of which should enhance one's optimism. Thus, we expect to find the following:

\section{Hypothesis 1: The greater the amount of psychosocial support provided by one's developmental network, the greater one's optimism.}

\section{Hypothesis 2: The greater the amount of career support provided by one's developmental network, the greater one's optimism.}

\section{The Importance of Beginnings: Early Developmental Support and Optimism}

A second way to examine the relationship between developmental network support and optimism is to look at how the timing of help-giving may be associated with optimism. Since careers scholars have written extensively about the lasting influence of beginnings, we consider this aspect of timing first. For example, how one starts off one's career in an organization, 
including the kinds of assignments one is given, can have a lasting impact on career advancement and professional development (Higgins, 2005; McCall, 1998). Here, we propose that developmental support provided during early career - that is, support provided during the first two years out of graduate school—will be related to optimism several years hence.

Consistent with prior boundaryless career research that has emphasized the role of supportive career relationships, recent positive organizational scholarship research suggests that positive work relationships encourage positive ways of interacting that affect future interaction patterns as well (Dutton \& Heaphy, 2003). Further, research has shown that people who experience a high degree of connectivity develop a capacity for exploring and creating new ideas (Losada \& Heaphy, 2004). Highly connective relationships such as these can open doors to new opportunities and experiences as well as fuel a desire for further connectivity and engagement in the future (Miller \& Stiver, 1977). Thus, we expect that starting one's post graduate career with a great deal of support from a network of developers will be associated with positive attitudes, including optimism, in the future.

In particular, we expect that individuals who began their careers with high amounts of psychosocial support from their developmental networks will have greater optimism than those who started off with developmental networks that weren't as strong. In organizational research, supportive interpersonal relationships have been positively associated with outcomes very similar to optimism, such as resilience, which is the capacity to bounce back from adversity (e.g., Maddi \& Khoshaba, 2005). As prior studies show, the socioemotional support received by early relationships with kin, teachers, role models, and peers enable people to better adapt, overcome setbacks, and excel despite the odds (Werner, 1993). Similarly, research on social support has shown that close relationships reduce the stress associated with adverse events (Gottlieb, 1983). 
Thus, here, we expect that individuals who had strong psychosocial support from a network of developers in the initial years following graduate school will have positive outlooks about their futures.

In addition, we expect that individuals who started off their careers with high amounts of career support, such as career-related sponsorship, coaching, and protection (Kram, 1985), will feel buffered and protected from stressors they face in their careers. Developmental networks that provide high amounts of career support post-graduate school tend to be positively associated with work satisfaction, intentions to remain (Higgins, 2000; Higgins \& Thomas, 2001), and high levels of career-related self-efficacy (Higgins, Dobrow \& Chandler, 2008). Such outcomes are consistent with a positive outlook on the future (Luthans, 2002; Schneider, 2001; see also Luthans, Avey, Avolio, Norman, \& Combs, 2006). Therefore, we expect that optimism will be positively related to the amount of help received early on in one's career:

Hypothesis 3: The greater the amount of psychosocial support provided early on in one's career by one's developmental network, the greater one's current optimism.

Hypothesis 4: The greater the amount of career support provided early on in one's career by one's developmental network, the greater one's current optimism.

\section{Changing Developmental Networks and Optimism}

A third way we consider the relationship between developmental support and optimism is to examine the extent to which change in developmental network strength may be related to optimism. One of the central themes in boundaryless career research has been the dynamic nature of careers - that is, the extent to which individuals change job functions, organizations and/or careers (e.g., Higgins, 2001). Since careers are tied to the relationships in which they are embedded, we, too, examine the dynamics of developmental relationships. Here, we consider career dynamics with respect to change in network strength. Specifically, we examine how the 
rate of change in the strength of support provided by one's developmental network over time is related to optimism several years hence.

Early adulthood, including the school-to-work transition, is often a time of significant change and challenge. People face increasing challenges as their lives progress and as they navigate tensions revolving around work, family, and the two spheres together (Halpern, 2005). And, although most current theories regarding adult development suggest that age and developmental stage are correlated but not deterministic (e.g., that an identity crisis does not occur at any predictable age), evidence suggests that individuals face numerous transitions that impact career, family, and self throughout adulthood (Levinson, Darrow, Klein, Levinson, \& Mckee, 1978; O’Connor \& Wolfe, 1991). We therefore expect that having networks that strengthen over time will be useful to young adults in dealing with increasing sets of challenges. Specifically, we expect that increasing amounts of psychosocial support will provide individuals with the emotional support necessary to refrain from adopting a pessimistic attributional style as they encounter inevitable stressors of young adulthood. As recent research shows, when individuals work in a climate of trust and respect, they tend to engage in behaviors that promote and sustain their own thriving at work (Spreitzer et al., 2005). Similarly, navigating one's career surrounded by developers whose support does not wane or stagnate but, rather, strengthens with time should be associated with higher levels of engagement in positive behaviors and attitudes such as optimism.

Further, increasing amounts of career support should provide individuals with skills and knowledge that facilitate the exploration of new possibilities and solutions to challenges. Increasing amounts of career support should foster a sense of competence, effectiveness (Kram, 1985), and optimism about their personal agency in obtaining positive outcomes in the future - 
that is, the feeling that good things will happen to them (Hale, Fiedler, \& Cochran, 1992; Scheier \& Carver, 1985). Therefore, we propose the following:

\section{Hypothesis 5: The rate of change of psychosocial support provided by one's developmental network will be positively associated with optimism.}

\section{Hypothesis 6: The rate of change of career support provided by one's developmental network will be positively associated with optimism.}

\section{Method}

\section{Sample and Procedure}

Participants in this study were students in a top-twenty United States East Coast full-time

MBA program. Survey data were collected at four points in time, spanning ten years (19962006). The first data collection ("Baseline") occurred before graduation in Spring 1996. ${ }^{1}$ All participants from the Baseline sample of 136 individuals were invited to complete the first follow-up survey approximately two years later in 1998 (“Time 1"). The response rate for this survey was $79 \%(\underline{n}=108)$. For the third survey ("Time 2"), which occurred in 2001, all participants from the Baseline sample were contacted to participate regardless of whether they had completed the Time 1 survey or not. The response rate was $64 \%(\underline{n}=87)$. The fourth data collection ("Time 3") occurred in 2006, ten years after graduation. ${ }^{2}$ Again, all participants from the Baseline sample were contacted to participate, regardless of whether they responded at Times 1 or 2 . The response rate was $57 \%(\underline{n}=77)$. A total of 408 surveys were collected across the four time points of the study.

\footnotetext{
${ }^{1}$ Of the 136 initial participants, 67 completed the 1.5 hour long survey during a group meeting (out of 87 in attendance; $77 \%$ response rate) and 69 completed the survey via mail (out of a random sample of 300; $23 \%$ response rate). Thus, the overall response rate was $35 \%$. There were no statistically significant differences between the two subsets of the Baseline sample with respect to any of the main variables of interest, and thus the two subsets were combined.

${ }^{2}$ The intervals between each data collection were chosen to span graduate school (Baseline) into early career at relatively regular intervals. These intervals are consistent with other longitudinal work on the career paths of MBA graduates (e.g., Reitman \& Schneer, 2005a, 2005b).
} 
Considering the physical mobility of this sample provides some insight into the extent to which these individuals had careers that would meet one of the possible definitions of a boundaryless career (Sullivan \& Arthur, 2006). Participants changed organizations between 3 and 4 times on average across the ten-year time frame, with a range from 1 to 6 organization changes. $^{3}$

\section{Optimism}

Consistent with the definition of state optimism that was used in research by Shifren and Hooker (1995, p. 61), "the current expectancy that positive outcomes will occur in the future," we used 25 optimism questions that were in a section of the survey that focused on current beliefs and expectations about the future. We used the 25-item revised generalized expectancy for success scale (GESS-R), which is considered a reliable measure of optimism (Hale, Fiedler, \& Cochran, 1992). Participants rated items with reference to the introductory statement, "In the future I expect that I will..." Sample items include “... succeed at most things I try” and "...handle unexpected problems successfully" (on a scale of $1=$ highly improbable to 5=highly probable). The score was determined additively $(\underline{\mathrm{M}}=102.97, \underline{\mathrm{S} . \mathrm{D}} .=10.66)$, with higher scores indicating higher levels of optimism. Optimism was measured at Time 3 (2006), the final time point in the study.

Although the GESS-R is generally used to capture trait levels of optimism, here, consistent with prior research (Kleumper et al., 2009), we had respondents reflect on their current feelings and thoughts about the future (e.g., within the last month), which reflects the notion of "current expectancy" rather than specific knowledge or appraisal constructs (Lazarus

\footnotetext{
${ }^{3}$ This number of organizations variable is an estimate based on the subset of our sample for whom we have complete employment records across the 10-year timeframe of the study $(n=65)$. This subset is too limited to incorporate into our regression analyses; however, this variable is not significantly correlated with any of the variables included in the analyses.
} 
1991, 1995). In this part of the survey and with regards to these questions, participants were therefore focusing on their feelings regarding their expectations of the future within a current timeframe, in contrast to a more permanent perspective, which is consistent with recent research on trait versus state-level optimism (Kluemper et al., 2009). Together, these factors suggest that we captured participants' state-like, rather than trait-like, optimism, consistent with recent work (see Luthans et al., 2007; Luthans, Avey, \& Patera, 2008). The internal consistency reliability of the scale was 0.92 .

\section{Developmental Network Measures}

On each survey, participants provided information about their current developmental network. Specifically, participants responded to a name generator question: "Please consider the people who you believe currently-i.e., some time over the last year-take an active interest in and concerted action to advance your career... they may be people with whom you work or have worked, friends, or family members.... and they may assist you with personal as well as professional development." Consistent with prior research, this question typically generated between four and five developers (e.g., Higgins, 2001). This question was asked independently at each time point (i.e., participants were not prompted with names mentioned in previous surveys).

For each developer named within a participant's developmental network, which totaled over 800 relationships across the sample over time, participants answered a variety of questions, including the type and amount of help provided by the developer, the hierarchical relationship of the developer (e.g., superior), and the origin of the mentoring relationship (e.g., school, community, etc.). In sum, our 10-year longitudinal dataset includes information on each 
participant's developmental network at each time period in which the participant responded. ${ }^{4}$

Participants' networks varied considerably. For example, the percentage of participants' developers who were from within the same organization ranged from none to all across Times 1 , 2, and 3 , and the means were $33 \%, 26 \%$, and $36 \%$, respectively. Likewise, the percentage of participants' developers who were fellow business school alumni were $14 \%, 12 \%$, and $8 \%$ at Times 1, 2, and 3, respectively. Thus, throughout the timeframe of the study, the majority of participants' developers came from outside of their own organizations and from outside of their business school cohort.

The developmental network measures relevant to our hypotheses are the amount of psychosocial and career support provided by developers in participants' developmental networks. On a 7-point scale, participants indicated the extent to which each of their developers provided different types of help: items such as "cares and shares in ways that extend beyond the requirements of work" and "is a friend of yours" indicated psychosocial support, and items such as "creates opportunities for visibility for you" and "opens doors for you professionally" indicated career support (where $1=$ never; not at all to $7=$ to the maximum extent possible) (Higgins \& Thomas, 2001). These items reflect previous mentoring research, both conceptual and empirical, that has described these two distinct types of mentoring support (e.g., Dreher \& Ash, 1990; Kram, 1985)

Developmental network strength was calculated as the average of the psychosocial or career support items for each participant-developer relationship and then the average across all dyadic relationships within each participant's developmental network. The average Baseline amount of psychosocial support in participants' developmental networks was 4.81 (S.D.=1.57);

\footnotetext{
${ }^{4}$ Analyses of the dynamics of the specific relationships named in these networks are reported elsewhere (see Cummings \& Higgins, 2005).
} 
for Time 1, 5.51 ( $\underline{\text { S.D. }}=.97)$; for Time 2, 5.68 ( $\underline{\text { S.D. }}=.89)$; and for Time 3, 5.50 ( $\underline{\text { S.D. }}=1.08)$. The average Baseline amount of career support was $3.02(\underline{\text { S.D. }}=1.52)$; for Time 1, $3.94(\underline{\text { S.D. }}=1.38)$; for Time 2, 4.03 ( $\underline{\text { S.D. }}=1.25)$; and for Time 3, 4.08 ( $\underline{\text { S.D. }}=1.42)$.

The Baseline survey occurred while our participants were in business school, whereas all subsequent surveys (Times 1, 2, and 3) occurred after they had graduated. Therefore, the Baseline developmental networks belonged to the participants while they were students, while the Times 1,2, and 3 networks belonged to them as professionals. Conceptually, there is a substantive difference between participants' life stages as students versus in their post-graduate careers. Thus, our analyses for Hypotheses 3 through 6 incorporate the repeated-measures nature of our developmental network data as follows. Our hypotheses examine questions about "earlycareer" network strength (Hypotheses 3 and 4) and the change in network strength over time (Hypotheses 5 and 6). "Early-career" network strength was operationalized as the amount of career or psychosocial support received by each participant at Time 1, the first survey postgraduate school when participants were no longer students. Change in the strength of participants' developmental networks—in terms of psychosocial or career support—was examined using participants' post-graduate school networks (Times 1,2, and 3). Measures of network strength from the Baseline survey were included in our analyses as control variables. This controls for pre-existing differences that may exist among individuals and allows us to focus specifically on the relationship between developmental support and optimism crosssectionally and over time.

\section{Controls}

Based on prior research on psychological capital (Luthans et al., 2008) and mentoring (e.g., Dobrow \& Higgins, 2005; Eby, Durley, Evans, \& Ragins , 2006), we controlled for the 
following demographic characteristics in our analyses: gender ( $72 \%$ male), age at the beginning of the study $(\underline{M}=27.8$, S.D. $=2.2)$, and level of education attained prior to business school $(77 \%$ college, 20\% master's degree, 4\% doctoral degree). Also consistent with prior mentoring research (Dobrow \& Higgins, 2005), we controlled for trait-level self-esteem, which was measured on the Baseline survey; these items, measured on a 7-point scale, were based upon

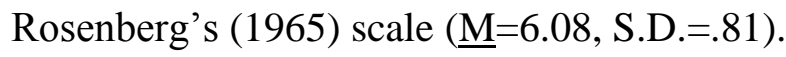

\section{Statistical Analyses}

We conducted two sets of multiple regression analyses to examine the extent to which developmental network strength was related to optimism at Time 3. Both included the same set of demographic controls, gender, age, level of education, and self-esteem. In the first, we tested the cross-sectional (i.e., within Time 3) Hypotheses 1 and 2 (Table 2, Model 1). Here, the focal network strength variables were the amount of psychosocial support at Time 3 and the amount of career support at Time 3. In the second, we used our longitudinal relational data to test Hypotheses 3 through 6 (Table 2, Model 2). Here, the focal network strength variables were early-career psychosocial support, early-career career support, change in psychosocial support over time, and change in career support over time. This model controlled for Baseline psychosocial support and Baseline career support.

The measures of early-career network strength and change in network strength used in our analyses were generated through multilevel modeling techniques (Singer \& Willett, 2003). ${ }^{5}$ In a first step, this type of model examines change in an outcome variable, such as network strength, over time by estimating a linear growth trajectory for each individual in the sample. Here, the two levels that comprise the multilevel model are within-individual ("level-1") and

\footnotetext{
${ }^{5}$ The data used in this study meet all of the requirements for applying multilevel modeling (Barnett, Marshall, \& Singer, 1992; Singer \& Willett, 2003).
} 
between-individuals ("level-2"). We fit two separate unconditional growth models—one for psychosocial support and one for career support—in which the passage of time was the only predictor of change in network strength (see Appendix 1). ${ }^{6}$ The level-1 and level-2 models can be combined into the following composite model:

$$
\hat{\mathrm{N}} \text { etwork Strength }{ }_{\mathrm{it}}=\hat{\beta}_{00}+\hat{\beta}_{10} \mathrm{YEAR}_{\mathrm{it}}
$$

Here, $\hat{N}$ etwork Strength ${ }_{i t}$ is the predicted value of the outcome variable (psychosocial or career support) for Person ${ }_{i}$ at $\mathrm{YEAR}_{\mathrm{t}}, \hat{\beta}$ o0 is the estimated intercept (the estimated value of the outcome when the predictor $\mathrm{YEAR}_{\mathrm{it}}=0$ (e.g., at Time 1 of the study), and $\hat{\beta} 10$ is the slope coefficient that quantifies the estimated amount of change in the outcome per year.

In a second step, the estimated intercept ( $\left.\hat{\beta}_{00}\right)$ and slope $\left(\hat{\beta}_{10}\right)$ generated for each individual by these multilevel models are used as the independent variables in the multiple regression models to test our hypotheses (see Table 2, Model 2). The intercept corresponds to "early-career" network strength (Hypotheses 3 and 4) and the slope corresponds to change in network strength over time (Hypotheses 5 and 6).

We used estimated intercepts and slopes from multilevel modeling as our measures of early-career network strength and change in network strength over time for several reasons. First, this method takes advantage of the multiple measures we collected at Times 1, 2, and 3. This results in a much more accurate representation of "true" developmental network strength during this career phase than would a single measure (Singer \& Willett, 2003). Second, this technique is much more flexible than traditional repeated measures analysis of variance as it does not require "balanced" data - that is, the same number of waves of data for each person (Singer

\footnotetext{
${ }^{6}$ Specifically, we fit multilevel models with both random intercepts and slopes, using SPSS's mixed procedure.
} 
\& Willett, 2003). Rather, all available waves of data from each individual are included and no imputation for missing data is needed (Singer \& Willett, 2003).

An alternative to using estimated intercepts and slopes would have been to use the "observed" network strength measure from Time 1 as the "early-career" indicator and the arithmetic difference between Time 1 and Time 3 as the measure of change. There has been considerable — and unresolved — debate in the literature about the robustness of using difference scores in analyses (see Willett, 1989 for a review). Further, calculating difference scores requires data from each individual at both Times 1 and 3. In our dataset, 67 individuals meet this requirement, whereas the multilevel modeling methodology generates an estimated slope for psychosocial support for 97 individuals and an estimated slope for career support for 96 individuals. These participants provided data during a minimum of any two of the three possible timepoints, for an average of 2.6 observations per person over time. ${ }^{7}$

Given the numerous methodological and conceptual concerns about using difference scores, including the reduction in the number of participants included in the analyses as well as the failure to take advantage of the benefits of having multiple measures over time, we opted to use the intercepts and slopes generated by multilevel modeling. ${ }^{8}$ Moreover, the correlations between observed Time 1 psychosocial support and the estimated intercept was .98; for career support it was also .98. The correlations between the difference score and estimated slope for psychosocial support was .85; for career support it was .99. These high correlations further support the use of estimated intercepts and slopes generated by our multilevel models.

\footnotetext{
${ }^{7}$ The data from participants who provided information about their developmental networks on only one of the three surveys ( $n=25$ for psychosocial; $n=27$ for career) contribute to the multilevel analyses (Singer \& Willet, 2003). However, estimates cannot be made for within-person variance for these individuals, and thus estimated intercepts and slopes are not generated. This accounts for the difference in sample size between the multilevel models in Appendix 1 and the number of participants described here.

${ }^{8}$ We ran a parallel set of analyses using the difference score method. We found a similar pattern of results for the early-career measures. The difference scores for both psychosocial and career support were not significant.
} 


\section{Results}

Descriptive statistics and correlations of all variables in these analyses are reported in Table 1. The mean of the optimism measure, 102.97 (S.D.=10.66) out of a 125-point maximum, indicates that participants experienced a relatively high level of optimism. Our multilevel models (see Appendix 1) established that developmental networks varied in both psychosocial and career strength across people over time. On a descriptive level, the data show that some people's network strength increased over time (psychosocial: 46\%; career: $42 \%$ ), some decreased (psychosocial: $39 \%$; career: 47\%), and some remained the same ${ }^{9}$ (psychosocial: 14\%; career: $10 \%)$.

Hypotheses 1 and 2 focused the relationship between developmental network strength and optimism from a cross-sectional perspective. Psychosocial support (Hypothesis 1) was positively and significantly associated with optimism $(\beta=3.83, \mathrm{p}=.01)$. Career support (Hypothesis 2) was not significantly associated with optimism. (See Table 2, Model 1).

[Insert Tables 1 and 2 about here]

Hypotheses 3 and 4 tested whether psychosocial and career support provided earlier on in one's career by one's developmental network were associated with greater optimism many years hence. Early-career psychosocial support (Hypothesis 3) was positively and significantly associated with optimism $(\beta=5.80, \underline{p}<.001)$, as was early-career career support (Hypothesis 4) $(\beta=3.70, p=.01) . \quad($ See Table 2, Model 2).

Hypotheses 5 and 6 tested whether increasing amounts of psychosocial and career support provided by one's developmental network were associated with greater optimism. We found that both change in psychosocial support over time (Hypothesis 5) $(\beta=38.63, \mathrm{p}=.001)$ and change in career support over time (Hypothesis 6$)(\beta=18.27, \mathrm{p}=.01)$ were significantly and

\footnotetext{
9 "Same" was defined as a rate of change between -.01 and .01 .
} 
positively related to optimism. (See Table 2, Model 2). These positive parameter estimates indicate that increasing amounts of both types of developmental support (from Time 1 through Time 3) were associated with higher levels of optimism experienced by participants at Time 3. Likewise, decreasing amounts of developmental support were associated with lower optimism at Time 3.

The magnitude of the relationship between developmental support—both from earlier in one's career and changing amounts over time - and optimism was substantial. Holding all other variables in the model constant, a person who experienced a high level of early-career psychosocial support (one standard deviation above the mean) and a high level of positive change in psychosocial support (one standard deviation above the mean) had a predicted optimism level 26.5 points higher (or $21 \%$ of the 125 -point scale) than a person who experienced a low level of early-career psychosocial support (one standard deviation below the mean) and a high level of negative change in psychosocial support (one standard deviation below the mean). The magnitude of the relationship between career support, both early-career and change over time, and optimism was also substantial. Here, the optimism level for a person who experienced high early-career career support (one standard deviation above the mean) and high positive change in career support (one standard deviation above the mean) was predicted to be 21.6 points higher (or $17 \%$ of the 125 -point scale) than a person with low early-career career support (one standard deviation below the mean) and high negative change in career support (one standard deviation below the mean).

\section{Discussion}

In the first issue on the boundaryless career in the Journal of Organizational Behavior (1994), scholars extended their perspective on careers beyond the traditional view of the 
"organization man" to consider the many ways that careers span boundaries including but not limited to those boundaries associated with a single employer. Today, we find reason to expand our purview even further. Beyond the notion of self-directed careers, which was central to the original work on boundaryless careers, the past decade plus of external shocks to the career environment (e.g., the dot-com boom and bust, 9/11, and the recent economic crisis) have reminded us that beyond the self, individuals' careers are interdependent. Building networks of support, such as the developmental networks studied here, can be extremely useful in navigating jolts that impact the career environment. As the present research suggests, the psychosocial support one receives from developers - from those who may or may not be associated with one's primary place of employment - may play a powerful role in protecting and/or bolstering one's ability to navigate the external forces that will inevitably come one's way in today's career environment.

From this interdependent perspective on careers, individuals and organizations alike must develop strategies for remaining flexible and adaptive, rather than rigid and reactive. They must develop what organizational scholars have termed "psychological capital," an overarching term for psychological capacities that include hope, optimism, and resilience (Luthans et al., 2007).

Although boundaryless career research has long promoted the idea of adaptability and the protean career (Mirvis \& Hall, 1994), the emphasis has been more on building social and human capital - that is, on what Arthur, Claman and DeFillippi (1995) refer to as "knowing whom" and "knowing how" respectively_rather than on building psychological capital, as was investigated here. In this study, we explored one facet of psychological capital—optimism — and the relationship it may have with the structure and quality of support individuals receive from their 
developmental networks. In the future, we hope that scholars will address other dimensions of psychological capital such as resilience and hope as important career capacities.

The notion of psychological capital and the facets that comprise it, such as optimism, have only just begun to emerge in organizational research (Kleumper et al., 2009). This new focus is consistent with research in positive organizational behavior, which focuses on individuals' strengths and capacities and the ways in which these can be developed to enhance performance (Luthans et al., 2007). Although some of this work has come under recent critique for being overly individualistic (e.g., Fineman, 2006), the present study departs from such an approach by considering the social context in which careers are embedded. By bringing in the literatures on positive organizational behavior and mentoring to the boundaryless careers literature, we begin to offer an interdisciplinary approach to the study of optimism, a novel and relevant career capacity in the current career environment.

Overall, our findings suggest a positive association between the strength of one's network of developmental relationships and optimism. This result derives from examining the relationship between developmental network strength and optimism in three different ways. First, we explored a cross-section of our data and found that psychosocial support but not career support was positively associated with optimism. Next, we examined "early-career" supportthat is, the amount and type of help provided in the initial years after graduate school—and its relationship with optimism eight years later. Controlling for stable factors such as self-esteem, we found that both psychosocial support and career support were positively related to optimism. And finally, with the benefit of having ten years of relational data, we examined how changes in developmental network strength were associated with optimism. Here, we also found positive 
relationships: developmental networks that increased in strength over time were positively associated with higher levels of optimism many years after graduate school.

The present study builds upon both central themes and new directions in the boundaryless career literature. Regarding central themes, the present study extends the early boundaryless career work on mentoring which stressed the importance of examining the composition and quality of networks of developmental support (e.g., Higgins \& Thomas, 1996). Developmental networks have been conceptualized as subsets of an individual's entire social network or social capital (Higgins \& Kram, 2001). Although the early boundaryless career research on social capital emphasized objective career outcomes, such as career advancement (e.g., Raider \& Burt, 1996), our study focused on a subjective career outcome, consistent with recent calls in career research (e.g., Hall \& Chandler, 2005; Heslin, 2005). This aligns well with Hall's (1996) relational approach to careers that focused on how individuals "lead more meaningful, psychologically successful lives" (p. 4).

Here, we build upon the idea in relational career theory and positive organizational theory that positive relationships are important (e.g., Spreitzer et al., 2005) and further, begin to assess in what ways relationships are helpful by examining the structure and quality of help provided. Additionally, we extend prior work by investigating the timing and also changing nature of support, a rare approach in career research. Instead, the focus has been on the presence or absence of close significant others such as peers, teachers, family, or counselors (e.g., Masten et al., 1999). Although we did not analyze the relationship between optimism and where specific relationships in these networks came from, we hope that in the future, researchers will examine the multiplicity of help-providers and combinations of support provided. This would help 
deepen our understanding of how facets of psychological capital such as optimism and networks of developmental support are related.

In terms of new directions for boundaryless careers research, this study highlights an approach to studying careers that emphasizes the significance of interdependence and the influence of events and people who envelop a "sequences of job experiences" (DeFillippi \& Arthur, 1994) - that is, who envelop a career. By taking a look at how relationships impact individuals' optimism across time, our work implies that rather than a purely self-directed approach or one in which a career is employer or context-free, as may have been implied by prior boundaryless careers research, it is important to consider how careers are inextricably linked to one important aspect beyond the self - the nexus of important relationships that influence one's career. Rather than independence, what we suggest here is renewed attention to the interdependence between individuals' careers and their environments - including but not limited to their networks of developmental relationships.

In addition to extending boundaryless career research, the present study builds upon recent calls in organizational research on optimism as well. Specifically, although scholars have examined the implications of optimism for job-related outcomes, they have called for greater attention to the antecedents of optimism and of state optimism in particular (Kluemper et al., 2009). Here, by examining the association between relational factors and state-level optimism and by doing so with longitudinal data on developmental networks, we begin to take steps toward answering this call. Beyond optimism, future research could focus on other aspects of psychological capital as well.

\section{Implications for Practice and Study Limitations}


The present research has both practical implications and limitations worthy of consideration. First, from a practical perspective, although instrumental career support, including career advice, exposure, and visibility, has been emphasized in prior research on careers (e.g., Ibarra, 1992, 1997), the findings from the present study begin to point to the critical role that psychosocial support may play in cultivating psychological resources such as optimism. To the extent that individuals are aware of the value of more socioemotional kinds of support in addition to instrumental kinds of support, employees may be better able to overcome challenges that will inevitably come their way. The present study extends prior research on instrumental support (e.g., advice about finding support that will help individuals learn new skills for the new career environment), by highlighting the potential value of "softer" forms of helpgiving and receiving. Being intentional about seeking out this kind of assistance is one possible implication of this study, and it is a novel and often-neglected aspect of navigating the ups and downs and boundarylessness of one's career (for recent research on helping, see Schein, 2009).

Second, our findings have implications for individuals reentering the workforce post graduate school. Oftentimes, individuals focus on finding a mentor during critical junctures in their careers - for example, when they first join an organization or first enter a new field. Here, we find that post-graduate school developmental support is indeed important and positively associated with psychological resources many years hence. Further, our findings regarding the changing nature of support begin to suggest that it is important to not only maintain but also cultivate these relationships, since strengthening networks in this study were also positively associated with optimism years later. Thus, another implication from our work is that individuals who continue to cultivate developmental relationships over the course of their careers 
may be better positioned in terms of withstanding inevitable career risks, stress, and hardships in today's career environment.

Our study has limitations in terms of its sample and design. First, we focused on a sample of people who have had opportunities that set them up better than, perhaps, the broader population, given the graduate school they attended. Still, since this was a cohort that launched post-graduate careers at the time the early boundaryless career research took hold, this group is a useful group in which to study questions about the boundaryless career environment. Extending this work to a broader representation of MBA programs, types of graduate schools, and populations would greatly enhance the generalizability of this research.

Second, our study is limited to the extent that we have a single source of information here - that is, self-report survey information. This approach is consistent with other mentoring and developmental network research in which questions are generally asked from the perspective of the respondent or "ego" (e.g., Higgins, 2001). Still, it would be interesting, in future research, to examine the extent to which the ties mentioned by the respondent were also named by the developer or "alter" as "developmental relationships.” Although difficult to collect, such data would enable us to investigate new questions such as how the mutuality of the relationships has an impact on the cultivation of important career outcomes.

Third, the design of our study would have been considerably stronger had we measured optimism at all points in time, as we did with our developmental network measures. Then, we could have conducted a cross-lagged panel analysis or employed multilevel models for change, which we were unable to do here. Unfortunately, we did not collect data on optimism when the study began in 1996. Indeed, many of the ideas regarding the importance of building psychological capacities have only emerged in positive psychology and organizational behavior 
within the last several years (see, for example, Luthans et al., 2007 on psychological capital). After the events of 9/11, when we heard our respondents claim that "nothing is safe anymore," we included new measures, including our measure of optimism, in the next data collection (Time 3). We selected the GESS-R measure of optimism (Hale, Fiedler, \& Chochran, 1992) because it was an extant, reliable measure of optimism. Our Time 3 data collection in 2006 predated the recently published measures of psychological capital (e.g., Luthans et al., 2007), and thus we were not able to include this measure. In the future, we hope that career scholars will build off of these ideas and our findings to collect longitudinal data that reflects the evolving nature of psychological resources such as optimism and their relationships to developmental networks.

Finally, our measures of optimism could have been improved considerably by more clearly distinguishing our measures as states, rather than traits. Specifically, rather than asking participants for their "current" assessments of optimism, we could also have modified the GESSR questions by adding the words "at work" at the end of each of our questions. In this way, we would have captured the context-specific nature of our construct (Peterson, 2000). We recommend this approach in future research.

\section{Conclusion}

This progression in our own thinking, from understanding that relationships are not simply gateways to new opportunities for career advancement but are also resources associated with important career capacities, echoes changes in the ways in which boundaryless career research has evolved. Building from the insight in 1994 that individuals must become more protean in their careers (Mirvis \& Hall, 1994), we may now be able to move forward to investigate what kinds of career capacities, including but not limited to optimism, enable individuals to do so. Further, we may now be able to take one step further, beyond the 
realization that careers are boundaryless to the notion that relationships that change and in which one's career is embedded may also span boundaries, and so, influence one's ability to navigate a turbulent career context. Finally, we may also explore the ways in which careers are not simply self-directed, as prior boundaryless careers research implied, but are also other-directed and in fact interdependent rather than independent from the relationships and employment context that envelop them. We hope that the present study inspires others to investigate these kinds of questions and to further examine developmental relationships as a critical career resource in the boundaryless career environment of today. 


\section{References}

Arthur, M.B. (1994). The boundaryless career: a new perspective for organizational inquiry. Journal of Organizational Behavior, 15, 295-306.

Arthur, M.B., Claman, P.H. \& DeFillippi, R.J. (1995). Intelligent enterprise, intelligent careers. Academy of Management Executive, 9, 7-20.

Arthur, M.B., \& Rousseau. D.M.(1996). The Boundaryless Career: A New Employment Principle for a New Organizational Era. New York: Oxford University Press.

Avolio, B.J., \& Luthans, F. (2006). High Impact Leadership: Moments Matter for Accelerating Authentic Leadership Development. New York: McGraw-Hill.

Barnett, R. C., Marshall, N.L., \& Singer, J. D. (1992). Job experiences over time, multiple roles, and women's mental health: A longitudinal study. Journal of Personality and Social Psychology, 62: 634-644.

Cameron, K.S., Dutton, J.E. \& Quinn, R.E. (2003). Positive Organizational Scholarship: Foundations of a New Discipline. San Francisco: Berrett-Koehler.

Cummings, J., \& Higgins, M.C. (2005). Relational instability at the core: Support dynamics in developmental networks. Social Networks, 28, 38-55.

DeFillippi, R.J., \& Arthur, M.B. (1994). The boundaryless career: a competency-based perspective. Journal of Organizational Behavior, 15, 307-324.

Dobrow, S., \& Higgins, M.C. (2005). Developmental networks and professional identity: A longitudinal study. Career Development International, 10, 567-583.

Dreher, G.F., \& Ash, R.A. (1990). A comparative study of mentoring among men and women in managerial, professional, and technical positions. Journal of Applied Psychology, 75, 539-547.

Dutton, J. \& Heaphy, E. (2003). Coming to Life: The power of high quality connections at work. In K. Cameron, J. Dutton and R. E. Quinn (Eds.), Positive Organizational Scholarship (pp. 263-278). San Francisco: Berrett-Koehler Publishers, Inc.

Eby, L.T., Durley, J.R., Evane, S.C., \& Ragins, B.R. (2006). The relationship between shortterm mentoring benefits and long-term mentor outcomes. Journal of Vocational Behavior, 69, 424-444.

Fineman, S., 2006. On being positive: Concerns and counterpoints. Academy of Management Review, 31, 270-291. 
Hale, D.H., Fiedler, L.R., \& Cochran, C.D. (1992). The revised generalized expectancy for success scale: A validity and reliability study. Journal of Clinical Psychology, 48(4), 517-521.

Hall, D.T. (1976). Careers in Organizations, Santa Monica, CA: Goodyear.

Hall, D.T. (1996). The Career is Dead-Long Live the Career: A Developmental Relational Approach to Careers. San Francisco: Jossey-Bass.

Hall, D.T., \& Chandler, D.E. (2005). Psychological success: When the career is a calling. Journal of Organizational Behavior, 26, 155-176.

Hall, D.T. \& Mirvis (1995). The new career contract: Developing the whole person at mid-life and beyond. Journal of Vocational Behavior, 47, 269-289.

Halpern, D.F. (2005). Psychology at the intersection of work and family: Recommendations for employers, working families, and policymakers. American Psychologist, 60, 397 409.

Heslin, P.A. (2005). Conceptualizing and evaluating career success. Journal of Organizational Behavior, 26, 113-136.

Higgins, M.C. (2000). The more, the merrier? Multiple developmental relationships and work satisfaction. Journal of Management Development, 19, 277-296.

Higgins, M.C. (2001). Changing careers: The effects of social context. Journal of Organizational Behavior, 22, 595-617.

Higgins, M.C. (2005). Career Imprints: Creating Leaders across an Industry. San Francisco: Jossey-Bass.

Higgins, M.C. (2007). A contingency perspective on developmental networks. In J. Dutton and B.R. Ragins (Eds.), Exploring Positive Relationships at Work: Building a Theoretical and Research Foundation (pp. 207-224). Hillsdale, NJ: Lawrence Erlbaum Associates.

Higgins, M.C., Dobrow, S.R., \& Chandler, D.E. (2008). Never quite good enough: The paradox of sticky developmental ties for elite university graduates. Journal of Vocational Behavior, 72, 207-224.

Higgins, M.C., \& Kram, K.E. (2001). Reconceptualizing mentoring at work: A developmental network perspective. Academy of Management Review, 26, 264-288.

Higgins, M.C., \& Thomas, D.A. (1996). Mentoring and the boundaryless career: Lessons from the minority experience. In M.B. Arthur and D.M. Rousseau (Eds.), The Boundaryless Career: A New Employment Principle for a New Organizational Era (pp. 268-281). New York: Oxford University Press. 
Higgins, M.C., \& Thomas, D.A. (2001). Constellations and careers: Toward understanding the effects of multiple developmental relationships. Journal of Organizational Behavior, 22, 223-247.

Ibarra, H. (1992). Homophily and differential returns: Sex differences in network structure and access in an advertising firm. Administrative Science Quarterly, 37, 422-447.

Ibarra, H. (1997). Paving an alternative route: Gender differences in managerial networks for career development. Social Psychological Quarterly, 60, 91-102.

Kluemper, D.H., Little, L.M., \& DeGroot, T. (2009). State or trait: effects of state optimism on job-related outcomes. Journal of Organizational Behavior, 30, 209-231.

Kram, K.E. (1985). Mentoring at Work: Developmental Relationships in Organizational Life. Glenview, IL: Scott Foresman.

Kram, K.E., \& Hall, D.T. (1989). Mentoring as an antidote to stress during trauma. Human Resource Management, 28, 493-510.

Kram, K.E., \& Hall, D.T. (1995). Mentoring in a context of diversity and turbulence. In L. Lobel \& E. Kossek (Eds.), Human Resource Strategies for Managing Diversity. London: Blackwell.

Lazarus, R.S. (1991). Emotion and Adaptation. New York: Oxford University Press.

Lazarus, R.S. (1995). Vexing research problems inherent in cognitive-mediational theories of emotion-and some solutions. Psychological Inquiry, 6, 183-196.

Levinson, D., Darrow, C., Klein, E., Levinson, M., \& Mckee, B. (1978). The Seasons of a Man's Life. New York: Knopf.

Livingston, J.S. (2003). Pygmalion in management. Harvard Business Review, January, 97106.

Losada, M., \& Heaphy, E. (2004). The role of positivity and connectivity in the performance of business teams: A non-linear dynamics model. American Behavioral Scientist, 47, 740765.

Luthans, F. (2002). The need for and meaning of positive organizational behavior. Journal of Organizational Behavior, 23, 695-706.

Luthans, F., Avey, J.B., Avolio, B.J., Norman, S.M., \& Combs, G. (2006). Psychological capital development: Toward a micro-intervention. Journal of Organizational Behavior, 27, 387-393. 
Luthans, F., Avey, J.B. \& Patera, J.L. (2008). Experimental analysis of a web-based microintervention on the learning and development of positive psychological states. Academy of Management Learning and Education, 7, 209-221.

Luthans, F., Avolio, B.J., Avey, J.B., \& Norman, S.M. (2007). Positive psychological capital: Measurement and relationship with performance and satisfaction. Personnel Psychology, $60,541-572$.

Luthans, F. \& Youssef, C.M. (2007). Emerging positive organizational behavior. Journal of Management, 33, 321-349.

Maddi, S.R., \& Khoshaba, D.M. (2005). Resilience at Work: How to Succeed No Matter What Life Throws at You. New York: Amacom.

Masten, A.S., Hubbard, J.J., Gest, S.D., Tellegen, A., Garmezy, N., \& Ramirez, M. (1999). Competence in the context of adversity: Pathways to resilience and maladaptation from childhood to late adolescence. Development and Psychopathology, 11, 143-169.

McCall, M.W. (1998). High Flyers: Developing the Next Generations of Leaders. Boston: Harvard Business School Press.

Miller, J.B., \& Stiver, I.P. (1977). The Healing Connection: How Women Form Relationships in Therapy and in Life. Boston: Beacon Press.

Mirvis, P.H. \& Hall, D.T. (1994). Psychological success and the boundaryless career. Journal of Organizational Behavior, 15, 365-380.

O’Connor, D., \& Wolfe, D.M. (1991). From crisis to growth at midlife: Changes in personal paradigm. Journal of Organizational Behavior, 12, 323-340.

Peterson, C. (2000). The future of optimism. American Psychologist, 55, 44-55.

Peterson, C. (2006). A Primer in Positive Psychology. New York: Oxford University Press.

Peterson, C. \& Seligman, M.E. (1984). Causal explanations as a risk factor for depression: Theory and evidence. Psychological Review, 91, 347-374.

Podolny, J.M., \& Baron, J.N. (1997). Relationships and resources: Social networks and mobility in the workplace. American Sociological Review, 62, 673-693.

Raider, H.J. \& Burt, R.S. (1996). Boundaryless careers and social capital. In M.B. Arthur, M. \& D.M. Rousseau (Eds.), The Boundaryless Career: A New Employment Principle for a New Organizational Era (pp. 187-200). New York: Oxford University Press. 
Reitman, F. \& Schneer, J.A. (2005a). The long-term negative impacts of managerial career interruptions: A longitudinal study of men and women MBAs. Group and Organization Management, 30, 243-262.

Reitman, F. \& Schneer, J.A. (2005b). The promised path: A longitudinal study of managerial careers. Journal of Managerial Psychology, 18, 60-75.

Rosenberg, M. (1965). Society and the Adolescent Self-Image. Princeton, NJ: Princeton University Press.

Scheier, M.F. \& Carver, C.S. (1985). Optimism, coping, and health: Assessment and implications of generalized outcome expectancies. Health Psychology, 4, 219-247.

Schein, E.H. (2009). Helping: How to Offer, Give, and Receive Help. San Francisco: BerrettKoehler.

Schneider, S.I. (2001). In search of realistic optimism. American Psychologist, 52, 250-263.

Seligman, M.E.P. (1998). Learned Optimism. New York: Pocket Books.

Seligman, M.E.P. (2002). Authentic Happiness: Using the New Positive Psychology to Realize Your Potential for Lasting Fulfillment. New York: Free Press/Simon and Schuster.

Seligman, M.E.P., \& Csikszentmihalyi, M. (2000). Positive psychology: An introduction. American Psychologist, 55, 5-14.

Shifren, K. \& Hooker, K. (1995). Stability and change in optimism: A study among spouse caregivers. Experimental Aging Research, 21, 59-76.

Singer, J.D. \& Willett, J.B. (2003). Applied Longitudinal Data Analysis: Modeling Change and Event Occurrence. Oxford; New York: Oxford University Press.

Spreitzer, G., Sutcliffe, K., Dutton, J., Sonenshein, S., \& Grant, A.M. (2005). A socially embedded model of thriving at work. Organization Science, 16, 537-549.

Strack, S., Carver, C.S., \& Blaney, P.H. (1987). Predicting successful completion of an aftercare program following treatment for alcoholism: The role of dispositional optimism. Journal of Personality and Social Psychology, 53, 579-584.

Sullivan, S.E., \& Arthur, M.B. (2006). The evolution of the boundaryless career concept: Examining physical and psychological mobility. Journal of Vocational Behavior, 69, 1929.

Thomas, D.A., \& Kram, K.E. (1988). Promoting career-enhancing relationships in organizations: The role of the human resource professional. In M. London \& E. Mone 
(Eds.), The Human Resource Professional and Employee Career Development (pp. 4666). New York: Greenwood.

Waterman, R.H., Waterman, J.A., \& Collard, B.A. (1994). Toward a career-resilient workforce. Harvard Business Review, July-August, 87-95.

Weick, C. (1996). Enactment and the boundaryless career: Organizing as we work. In M.B. Arthur, M. \& D.M. Rousseau (Eds.), The Boundaryless Career: A New Employment Principle for a New Organizational Era (pp. 40-57). New York: Oxford University Press.

Werner, E.E. (1993). Risk, resilience, and recovery: Perspectives from the Kauai longitudinal study. Development and Psychopathology, 5, 503-515.

Willett, J.B. (1989). Questions and answers in the measurement of change. Journal of Research in Education, 15, 345-422.

Whitely, W., Dougherty, T.W., \& Dreher, G.F. (1991). Relationship of career mentoring and socioeconomic origin to managers' and professionals' early career progress. Academy of Management Journal, 34, 331-351.

Whyte, W. (1956). The Organization Man. New York: Simon and Schuster.

Youssef, C.M. \& Luthans, F. (2007). Positive organizational behavior in the workplace: The impact of hope, optimism, and resilience. Journal of Management, 33, 774-800.

Zey, M. (1984). The Mentor Connection. Homewood, Il.: Dow Jones-Irwin. 
Optimism and the Boundaryless Career 38

Table 1. Means, standard deviations, and correlations ${ }^{\mathrm{a}}$

\begin{tabular}{|c|c|c|c|c|c|c|c|c|c|c|c|c|c|c|}
\hline & $X$ & S.D. & 1 & 2 & 3 & 4 & 5 & 6 & 7 & 8 & 9 & 10 & 11 & 12 \\
\hline 1. Gender ${ }^{b}$ & 0.28 & 0.45 & & & & & & & & & & & & \\
\hline 2. $\mathrm{Age}^{\mathrm{c}}$ & 27.82 & 2.23 & -0.13 & & & & & & & & & & & \\
\hline 3. Level of education ${ }^{\mathrm{d}}$ & 1.27 & 0.52 & -0.14 & $0.26 * *$ & & & & & & & & & & \\
\hline 4. Self-esteem ${ }^{\mathrm{e}}$ & 6.07 & 0.81 & 0.03 & -0.10 & $-0.17 *$ & & & & & & & & & \\
\hline 5. Time 3 network strength: psychosocial $^{\mathrm{f}}$ & 5.50 & 1.08 & 0.05 & -0.02 & 0.03 & 0.05 & & & & & & & & \\
\hline 6. Time 3 network strength: career ${ }^{\mathrm{f}}$ & 4.08 & 1.42 & 0.14 & 0.03 & -0.08 & 0.18 & $0.30 * *$ & & & & & & & \\
\hline 7. Baseline network strength: psychosocial $^{\mathrm{f}}$ & 4.81 & 1.57 & 0.04 & -0.07 & -0.14 & 0.08 & 0.11 & 0.05 & & & & & & \\
\hline 8. Baseline network strength: career $^{\mathrm{f}}$ & 3.02 & 1.52 & 0.09 & -0.07 & -0.06 & 0.04 & 0.12 & 0.22 & $0.70 * *$ & & & & & \\
\hline 9. Early-career network strength: psychosocial $^{\mathrm{f}}$ & 5.54 & 1.02 & 0.10 & -0.08 & -0.05 & $0.22 *$ & 0.17 & -0.05 & $0.23 *$ & 0.14 & & & & \\
\hline 10. Early-career network strength: career $^{\mathrm{f}}$ & 3.98 & 1.45 & 0.02 & 0.07 & -0.03 & $0.30 * *$ & 0.03 & 0.19 & 0.03 & $0.24 *$ & 0.17 & & & \\
\hline 11. Change in network strength: psychosocial $^{\mathrm{g}}$ & 0.02 & 0.19 & 0.02 & -0.01 & 0.06 & -0.11 & $0.62 * *$ & $0.29 *$ & -0.09 & -0.02 & $-0.64 * *$ & 0.02 & & \\
\hline 12. Change in network strength: career $^{g}$ & 0.03 & 0.30 & $0.24 *$ & -0.04 & 0.02 & $-0.25 *$ & $0.25 *$ & $0.56 * *$ & 0.03 & 0.03 & -0.11 & $-0.68 * *$ & 0.07 & \\
\hline 13. Optimism ${ }^{\mathrm{h}}$ & 102.97 & 10.66 & 0.21 & -0.01 & -0.15 & $0.54 * *$ & 0.24 & 0.21 & -0.15 & -0.06 & $0.30 *$ & $0.41 * *$ & -0.01 & -0.25 \\
\hline
\end{tabular}

Notes: ${ }^{*} \mathrm{p} \leq .05,{ }^{* *} \mathrm{p} \leq .01 ;$ a pairwise correlations resulted in range of $\mathrm{n}=57$ to $\mathrm{n}=136 ;{ }^{\mathrm{b}} 0=$ male; $1=$ female; ${ }^{\mathrm{c}}$ Age in years at Baseline; ${ }^{\mathrm{d}} 1=$ college; $2=$ master's degree; $3=$ doctoral degree; ${ }^{\mathrm{e}} 1=\mathrm{low}$ self-esteem to $7=$ high self-esteem; ${ }^{\mathrm{f}}$ Offers this type of support $1=$ never; not at all to $7=$ to the maximum extent possible; ${ }^{\mathrm{g}}$ Amount of change (on 7 -point scale) from Time 1 to Time $3 ;{ }^{\mathrm{h}}$ Sum of 25 items rated on a 5 -point scale; 125 points maximum. 
Table 2. Multiple regression models for Hypotheses 1 through 6: the relationship between developmental network strength variables and optimism

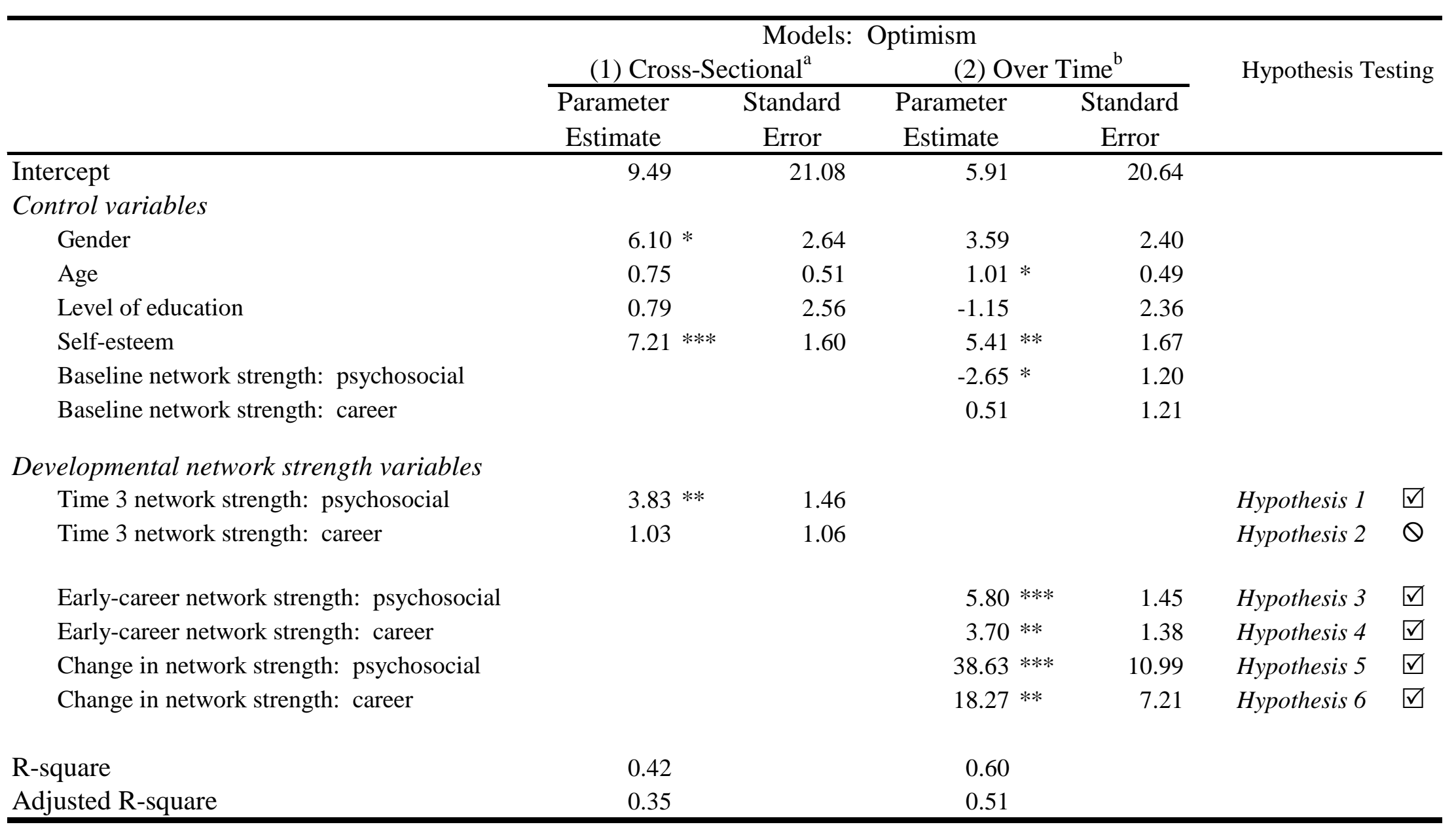

Notes: ${ }^{\mathrm{t}} \mathrm{p} \leq .10 .{ }^{*} \mathrm{p} \leq .05, * * \mathrm{p} \leq .01,{ }^{* * *} \mathrm{p} \leq .001 .{ }^{\mathrm{a}} \mathrm{n}=58$; within Time 3 (2006; last wave of longitudinal data collection); ${ }_{\mathrm{n}}^{\mathrm{b}}=55$; from Times 1 to 3 (1998-2006). 


\section{Appendix 1. Multilevel models: The effect of time on psychosocial and career support}

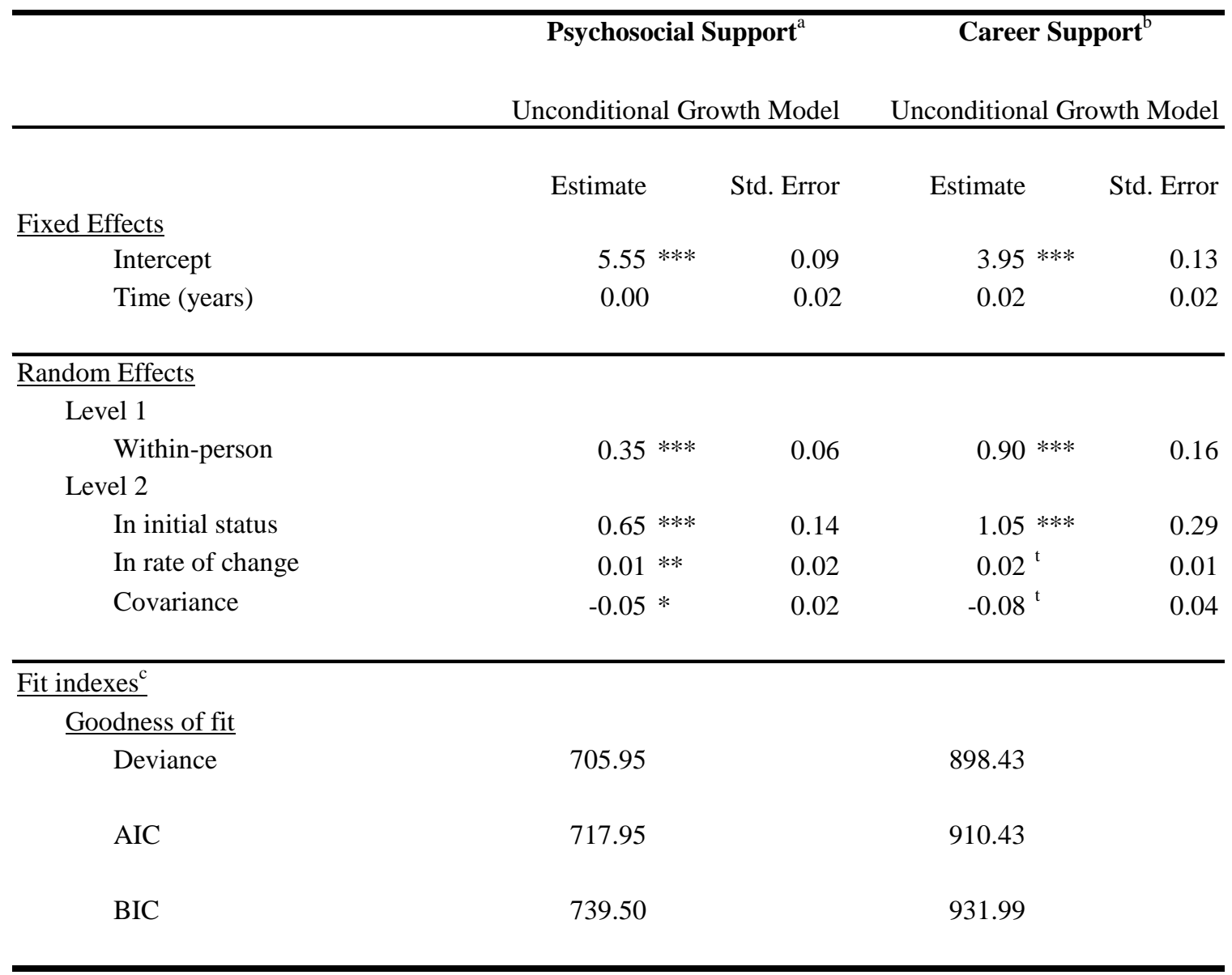

Notes: ${ }^{\mathrm{t}} \mathrm{p} \leq .10 .{ }^{*} \mathrm{p} \leq .05,{ }^{* *} \mathrm{p} \leq .01,{ }^{* * *} \mathrm{p} \leq .001 .{ }^{\mathrm{a}} \mathrm{n}=122 ;{ }^{\mathrm{b}} \mathrm{n}=123 ;{ }^{\mathrm{c}}$ Deviance $=-2$ log likelihood; AIC $=$ Akaike's information criterion; BIC $=$ Bayesian information criterion. SPSS mixed models. 